Bundesgesundheitsbl 2020 - 63:45-55 https://doi.org/10.1007/s00103-019-03070-1 Online publiziert: 11 . Dezember 2019 (c) Springer-Verlag GmbH Deutschland, ein Teil von Springer Nature 2019

\section{Geschichte der Impfstoff- entwicklung gegen Malaria}

Die Geschichte der Malariavakzine begann bereits vor über 100 Jahren, als die Brüder Sergent bei algerischen Kanarienvögeln durch die Impfung mit hitzeinaktivierten Sporozoiten (infektiöses Stadium des Malariaparasiten Plasmodium) eine Teilimmunität gegen Vogelmalaria ( $P$. relictum) hervorrufen konnten [1]. Der Startschuss für die moderne Forschung zur Entwicklung eines Malariaimpfstoffes war der Einsatz röntgenbestrahlter Sporozoiten zum Schutz vor Mäusemalaria (P. berghei) in den 1960er-Jahren [2].

In einer richtungsweisenden Publikation aus den 1970er-Jahren wird von einem Freiwilligen berichtet, der durch den Stich röntgenbestrahlter Moskitos mit Sporozoiten von P. falciparum, dem Erreger der tropischen Malaria (Malaria tropica), infiziert wurde und daraufhin gegen die Infektion mit unbestrahlten Sporozoiten geschützt war [3]. In den 1980er-Jahren waren die Erwartungen an einen Sporozoitenimpfstoff dann so groß [4], dass die beteiligten Forscher ein Patent aufSporozoitenantigene anmeldeten [5]. Dies war jedoch verfrüht, da ein wirksamer Impfstoff nicht hergestellt werden konnte [6].

In den 1990er-Jahren wurde der kolumbianische Wissenschaftler Manuel Patarroyo als Held der Malariakranken gefeiert, weil er das Patent seines neuentwickelten Impfstoffes SPf66 („Serum Plasmodium falciparum Version 66") der Weltgesundheitsorganisation (WHO) vermachte [7]. Der Impfstoff erwies sich jedoch in afrikanischen Feldstudien als unwirksam und wurde von der WHO

Wolfram Gottfried Metzger · Zita Sulyok · Antje Theurer · Carsten Köhler

Institut für Tropenmedizin, Reisemedizin und Humanparasitologie, Kompetenzzentrum Tropenmedizin Baden-Württemberg, Universitätsklinikum Tübingen, Tübingen, Deutschland

\title{
Entwicklung von Impfstoffen gegen Malaria - aktueller Stand
}

nicht eingesetzt [8]. Wenig bekannt ist, dass geimpfte Kinder mit hohen Antikörpertitern gegen SPf66 bis zu zwei Jahre nach der Impfung mehr Malariaepisoden hatten als ungeimpfte Kontrollkinder [9, 10].

Die WHO nannte in der Malaria Vaccine Technology Roadmap (2006, 2013) das Ziel, bis zum Jahr 2030 effiziente Impfstoffe gegen $P$. falciparum und $P$. vivax zu entwickeln. Die Impfstoffe sollen eine Wirksamkeit von mindestens $75 \%$ gegen Malaria haben und für den Einsatz im endemischen Gebiet geeignet sein. Dies bedeutet, dass die Schutzwirkung wenigstens 2 Jahre anhalten und eine Boosterimpfung höchstens einmal im Jahr notwendig sein soll [11]. Aus Gründen der Platzersparnis wird die Entwicklung von Impfstoffen gegen weniger gefährliche Malariaerreger, wie z. B. P. vi$v a x$, in dieser Arbeit nicht beschrieben.

Das steigende Interesse an Malariaimpfstoffen spiegelt sich in einer wachsenden Anzahl publizierter Artikel wider. So lassen sich seit Anfang des Jahres 2018 mehr als 30 Übersichtsarbeiten $\mathrm{zu}$ verschiedenen Aspekten der Malariaimpfstoffentwicklung in PubMed, der Datenbank der National Library of Medicine, finden.

Der heute am weitesten entwickelte Impfstoff gegen $P$. falciparum ist RTS,S/AS01 (Mosquirix ${ }^{\mathrm{Ts}}$, GlaxoSmithKline, Brentford, UK). Auch hier waren die Erwartungen so hoch, dass die Fermenter (Gärtanks) zur massenweisen Herstellung des Impfstoffes schon bereitstanden, bevor die Ergebnisse der Wirksamkeitsstudien bekannt waren [12]. Mit einer Wirksamkeit von ca. 30\% gegen unkomplizierte Malaria bei Kindern [13] wird RTS,S/AS01 nach drei
Jahrzehnten Forschungsarbeit seit April 2019 in großangelegten Pilotkampagnen in afrikanischen Ländern südlich der Sahara eingesetzt [14]. Von ca. 70 Impfstoffkandidaten ist er damit der erste Malariaimpfstoff, der eine Phase-4-Studie unter realen epidemiologischen und operativen Bedingungen im Hochendemiegebiet erreicht.

Es stellt sich die Frage, ob mit diesem Erfolg nun die erste oder die letzte Runde im Rennen um die Entwicklung eines wirksamen Malariaimpfstoffes eingeläutet ist.

\section{Malariaerkrankung und -bekämpfung}

Im Jahr 2017 erkrankten laut Schätzungen der WHO weltweit 219 Mio. Menschen an der Malaria, 435.000 starben, davon mehr als $90 \%$ im tropischen Afrika. Mehr als $60 \%$ der Todesfälle betreffen Kinder unter 5 Jahren. Knapp die Hälfte aller Erkrankungsfälle tritt in fünf Ländern auf: Nigeria (25\%), Demokratische Republik Kongo (11\%), Mosambik (5\%), Uganda (4\%) und Indien (4\%; WHO 2018). In Deutschland wurden 927 importierte Malariaerkrankungen für das Jahr 2017 gemeldet, wobei $93 \%$ dieser Infektionen im tropischen Afrika erworben waren. Drei der Fälle verliefen tödlich [15]. Nach einem Rückgang bis zum Jahr 2016 steigen die globalen Fallzahlen und Todesraten wieder an.

Malaria ist eine parasitäre Erkrankung, die von Einzellern, sog. Plasmodien, verursacht wird und für Nichtimmune lebensgefährlich sein kann. Es werden momentan fünf humanpathogene Spezies unterschieden, die sich morphologisch sowie in der klinischen 
Symptomatik unterscheiden: $P$. falciparum, $P$. vivax, $P$. ovale, $P$. knowlesi, P. malariae. Die am häufigsten vorkommende Spezies, die fast alle Todesfälle herbeiführt, ist $P$. falciparum mit unregelmäßigen Fieberspitzen: In Afrika verursacht $P$. falciparum über $99 \%$, in Südostasien $63 \%$ der Malariafälle. In Lateinamerika ist $P$. vivax, der Erreger der sog. tertianen Malaria (Fieberspitzen alle $48 \mathrm{~h}$ ), mit $74 \%$ die häufigste Spezies mit hoher Krankheitslast (Disease Burden). In Asien verursacht $P$. vivax fast die Hälfte der Fälle, wohingegen dieser Parasit in Subsahara-Afrika fast nicht vorkommt. P. ovale, ein anderer Erreger der tertianen Malaria, tritt wiederum ausschließlich in Ländern Zentral- und Westafrikas auf. P. knowlesi (tägliche Fieberspitzen) ist ein Erreger der Affenmalaria in Südostasien, der erst kürzlich auch als Ursache humaner Malaria identifiziert wurde. Zur Krankheitslast der weltweit verbreiteten quartanen Malaria ( $P$. malariae, Fieberspitzen alle $72 \mathrm{~h}$ ), die ein großes Tierreservoir hat, gibt es nur wenige Untersuchungen [16].

Da die tropische Malaria medikamentös therapiert werden kann und bei richtiger Behandlung keine Spätschäden nach sich zieht, können Freiwillige unter kontrollierten Bedingungen mit P. falciparum infiziert werden (Controlled Human Malaria Infection [CHMI]). Experimentelle Malariainfektionen am Menschen haben eine lange Tradition. Da die Medizingeschichte zeigt, dass Experimente am Menschen auch in krimineller Weise durchgeführt werden können, wie in Deutschland zwischen 1933 und 1945, unterliegen sie heutzutage strengen $\mathrm{Re}$ gulierungen [17]. Grundsätzlich ist die experimentelle Infektion von gesunden Freiwilligen eine äußerst nützliche Methode, um mit wenig Aufwand und in kurzer Zeit Medikamente und Impfstoffe zu testen und/oder immunologische Erkenntnisse zu gewinnen, was im Speziellen auch auf die Malariainfektion zutrifft [18].

Die Therapeutika der ersten Wahl in endemischen Gebieten sind Kombinationspräparate mit Artemisinin (ACT), gegen die sich aber in Südostasien bereits Resistenzen entwickelt haben [19]. Durch frühzeitige Diagnose und Behand- lung werden schwere klinische Verläufe und letale Ausgänge meist verhindert. Die hohe Mortalität im tropischen Afrika ist in erster Linie der Armut der Bevölkerung geschuldet: Häufig können die Mittel für den Transport zum nächsten Gesundheitsposten oder Krankenhaus nicht oder nicht rechtzeitig aufgebracht werden, wenn ein Kind die ersten grippeähnlichen Symptome zeigt [20]. Dementsprechend kann Malaria als Armutskrankheit bezeichnet werden [21].

Der wichtigste Überträger (Vektor) von Malaria ist die Anophelesmücke. Auch hier kann die Bekämpfung der Malaria ansetzen, indem die Brutplätze der Moskitos eliminiert werden. Hauptpfeiler der Vektorkontrolle ist der Gebrauch von Bettnetzen, die mit Insektiziden imprägniert sind, sowie das sog. Indoor Spraying. Zudem schlägt die WHO eine intermittierende präventive Therapie mit Sulfadoxin/Pyrimethamin für Schwangere und Kinder unter 5 Jahren vor, die in Gebieten mit hohem Malariarisiko leben. Reisenden in Hochendemiegebiete wird neben der Expositionsprophylaxe eine kontinuierliche Chemoprophylaxe angeraten [22].

Menschen, die ständig in Gebieten mit hohem Malariarisiko leben, entwickeln nach einigen Jahren und mehr als 20 Malariaepisoden [23] eine sog. Semiimmunität, die schwere Krankheitssymptomatik bzw. Letalität verhindert. Allerdings wird in der Regel keine sterile Immunität erreicht [24], d.h., die Parasiten im Blut können nicht eliminiert werden, sodass die Transmission der Parasiten durch die Semiimmunität nicht unterbrochen wird. Das ehrgeizige Ziel der Malariaforschung ist die Entwicklung einer Immunisierungsstrategie, die einen Schutz bewirkt, der die natürlich erworbene Semiimmunität übertrifft.

Der Lebenszyklus von Plasmodien ist komplex (• Abb. 1): Weibliche Anophelesmücken stechen, weil sie Blut für die Reifung ihrer Eier brauchen. Während der Blutmahlzeit der Mücke werden die Malariaparasiten im Sporozoitenstadium auf den Menschen übertragen. Über die Blutbahn gelangen die Sporozoiten innerhalb von $10-30 \mathrm{~min}$ in die Leber, wo sie sich teilen (Leberschizogonie) und ca. eine Woche verweilen (sog. Leberpha- se). Die klinische Symptomatik beginnt in der sog. erythrozytären Phase, d.h. kurz nachdem die Plasmodien - aus der Leber kommend - in die Blutbahn eingedrungen sind, wo sie sich als asexuelle Formen (sog. Merozoiten, Trophozoiten, Schizonten) in den roten Blutkörperchen zyklisch vermehren, was zu charakteristischen Fieberschüben führt. Der Kreislauf schließt sich, wenn sexuelle Formen des Parasiten (sog. Gametozyten) auftreten, die von einer weiteren Anophelesmücke aufgesaugt werden, um sich in deren Magen zu paaren und wieder Sporozoiten zu bilden. Der sog. sporogonische Teilzyklus im Mückenmagen dauert 1-2 Wochen. Impfstoffe können potenziell an verschiedenen Stellen in den Lebenszyklus der Plasmodien eingreifen.

\section{Impfstoffe gegen Malaria}

Die drei Phasen im Lebenszyklus der Plasmodien (• Abb. 1) sind die Ansatzpunkte für die Impfstoffentwicklung:

1. Präerythrozytäre Impfstoffe immunisieren gegen die Parasiten auf dem Weg von der Einstichstelle in die Leber (Sporozoiten) und während ihres Aufenthaltes in der Leber (Übergang vom Sporozoiten zum Leberschizonten).

2. Erythrozytäre Impfstoffe immunisieren gegen die Parasiten, die sich im Blut in asexueller Weise zyklisch vermehren (Merozoiten, Trophozoiten, Schizonten).

3. Transmissionsblockierende Impfstoffe immunisieren gegen die sexuellen Formen des Parasiten (Gametozyten, Wirkort ist der Mückenmagen).

4. Multistadiumimpfstoffe (Multi-stage Vaccines) sind Kombinationsimpfstoffe mit Impfantigenen aus den verschiedenen Stadien des Zyklus.

Eine nomenklatorische Sonderrolle nehmen
5. Plazentaimpfstoffe und

6. DNA-Vakzinen

ein, da hier ein menschliches Organ bzw. die molekulare Struktur des Impfstoffs als Namensgeber dient.

Zusätzlich kann - wie bei anderen Impfstoffen auch - zwischen Ganzzell- 
Bundesgesundheitsbl 2020 ·63:45-55 https://doi.org/10.1007/s00103-019-03070-1

(c) Springer-Verlag GmbH Deutschland, ein Teil von Springer Nature 2019

\section{W. G. Metzger $\cdot$ Z. Sulyok $\cdot$ A. Theurer $\cdot$ C. Köhler}

\section{Entwicklung von Impfstoffen gegen Malaria - aktueller Stand}

\section{Zusammenfassung}

Weltweit leben 3,1 Mrd. Menschen in Gebieten, in denen Malaria endemisch ist (Tropen, Subtropen). Jährlich erkranken etwa 200 Mio. Menschen, ca. 500.000 sterben daran. Betroffen sind vor allem Kinder. Um die Malaria zu kontrollieren und schlussendlich jegliche Neuinfektion zu verhindern, ist die Entwicklung wirksamer Impfstoffe von großer Bedeutung. In diesem Beitrag werden zunächst Hintergrundinformationen zur Geschichte der Impfstoffentwicklung, zur Malariaerkrankung und zu den Möglichkeiten der Therapie und Ausbreitungskontrolle gegeben. Der Hauptteil widmet sich dem aktuellen Forschungsstand zu Impfstoffen gegen den Erreger Plasmodium falciparum, gefolgt von einer ausführlichen Diskussion.
Malaria ist eine parasitäre Infektionskrankheit, die von Einzellern, sog. Plasmodien, verursacht wird. Es werden 5 humanpathogene Spezies unterschieden, von denen $P$. falciparum über $99 \%$ der Erkrankungen in Afrika verursacht. Überträger (Vektor) ist die Anophelesmücke. Plasmodium bietet innerhalb seines Lebenszyklus verschiedene Ansatzpunkte für die Wirkung von Impfstoffen. Von den insgesamt ca. 70 Impfstoffkandidaten sind die präerythrozytären Impfstoffe, die in den Leberzyklus des Parasiten eingreifen, aktuell am weitesten entwickelt. Die von der Weltgesundheitsorganisation (WHO) angestrebte Wirksamkeit von mindestens $75 \%$ wurde aber längst nicht erreicht. Mit RTS,S/AS01 wird derzeit erstmals ein mäßig wirksamer Impfstoff großflächig eingesetzt. Schon jetzt ist offensichtlich, dass die Malaria nur im Zusammenspiel mit anderen Maßnahmen eingedämmt werden kann. Expositionsprophylaxe mit imprägnierten Moskitonetzen, der Einsatz von Insektiziden mit Residualeffekt in Innenräumen (Indoor Residual Spraying), die Vernichtung von Moskitobrutplätzen und schnelle Diagnose und Therapie der Erkrankung sind hier wichtige Elemente ebenso wie eine funktionierende Gesundheitsversorgung, die in den von Armut geprägten Gebieten oft nicht gewährleistet ist.

\section{Schlüsselwörter}

Malariaimpfstoff · Malariakontrolle · Wirksamkeit der Impfung · Präerythrozytäre Impfstoffe $\cdot$ RTS,S

\section{Development of malaria vaccines-state of the art}

\section{Abstract}

Globally, 3.1 billion people live in areas endemic for malaria (the tropics and subtropics). Annually, around 200 million fall ill, and around 500,000 persons die as a result of this infection. Mainly children are the victims. In order to control and eventually prevent any new infection, the development of effective vaccines is pivotal. In this review, background information about the history of vaccine development and malaria disease as well as possibilities for therapy and control is given. In the main part of the article, an update on the development of vaccines against Plasmodium falciparum is provided followed by an extensive discussion.
Malaria is a parasitic infectious disease caused by the single cell organism Plasmodium. Five different Plasmodium species can induce disease in humans with $P$. falciparum being the origin for more than $99 \%$ of infections in Africa. The vector is the Anopheles mosquito. The life cycle of Plasmodium offers several approaches for vaccines to have an impact. Out of around 70 candidates, pre-erythrocytic vaccine candidates interfering with the liver phase of the parasite are the most developed. However, a vaccine with more than $75 \%$ efficacy, as required by the World Health Organization (WHO), is not yet in sight. Currently, for the first time, a moderately efficacious vaccine (RTS,S/AS01) is being applied in large-scale operations. But it is obvious that malaria can only be controlled in combination with concurring measures. For example, the use of impregnated mosquito nets, indoor residual spraying, elimination of vector breeding sites, rapid diagnosis, and therapy of the infection as well as a functioning health system are important elements, which can hardly be guaranteed in areas characterized by poverty.

Keywords

Malaria vaccine $\cdot$ Malaria control $\cdot$ Vaccine efficacy · Pre-erythrocytic vaccine $\cdot$ RTS,S und Untereinheitenvakzinen sowie zwischen Tot- und Lebendimpfstoffen unterschieden werden. Adjuvanzien (Hilfsstoffe) sind von zentraler Bedeutung, da sie die Immunantwort gegen das Impfantigen steigern. Bei einigen Forschungsansätzen werden Malariaantigene in pädiatrische Impfstoffe integriert.

Ein zentrales Problem bei der Entwicklung von Impfstoffen gegen Malaria ist die hohe antigene Variabilität von $P$. falciparum. Häufig, insbesondere in frühen Phasen der klinischen Prüfung, wird die Wirksamkeit einer Impfung mit dem homologen Stamm getestet, der identisch mit dem Impfstamm ist; daraus ergibt sich naturgemäß eine tendenziell bessere Wirksamkeit als bei natürlichen Infektionen. Ansätze, diesem Problem zu begegnen, beinhalten die Verwendung nichtvariabler (konservierter) Antigene, die bei allen Stämmen vorkommen, oder zahlreicher verschiedener Antigene.

Laut den sog. Regenbogentabellen, in denen die WHO-Initiative für Impfstoffforschung (IVR) alle klinischen und fort- geschrittenen präklinischen Aktivitäten von Malariaimpfstoffprojekten aufzeichnet, werden zurzeit 21 klinische Studien mit Impfstoffkandidaten durchgeführt: jeweils 9 Studien mit präerythozytären bzw. erythrozytären Impfstoffen und 9 Studien mit transmissionsblockierenden Impfstoffen (16 Phase-1-Studien, 4 Phase-2-Studien, 1 Phase-4-Studie; $[25,26])$.

Im Folgenden werden die am weitesten entwickelten Impfstoffe in den oben genannten Kategorien vorgestellt. 
Malaria

(Plasmodium spp.)

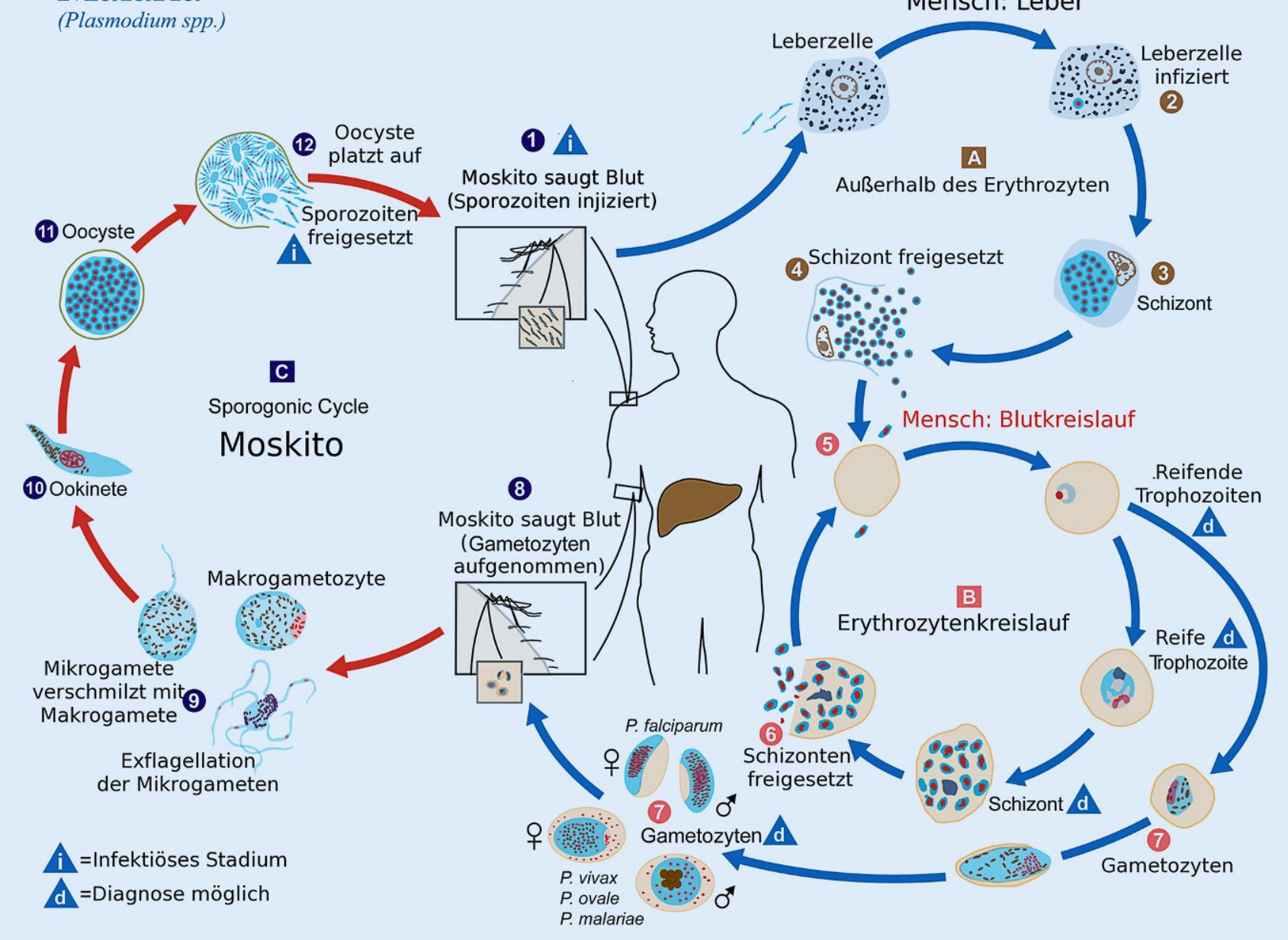

Abb. 1 A Lebenszyklus der Plasmodien am Beispiel der Malaria beim Menschen. (Quelle: Wikimedia Commons, https:// commons.wikimedia.org/wiki/File:Plasmodium_zyklus.png)

Die Auswahl gründet sich auf Einzelpublikationen, Übersichtsarbeiten und Daten der WHO [27]. Impfstoffkandidaten, die in der jeweiligen Kategorie erst am Beginn der Entwicklungslinie stehen, werden nicht vollständig aufgeführt. Hier wird auf das umfangreiche Datenmaterial der WHO [27] und ausgewählte Übersichtsarbeiten verwiesen $[13,26,28]$. Da präerythrozytäre Impfstoffe am weitesten fortgeschritten sind, wird dieser Gruppe im Folgenden der größte Raum beigemessen.

\section{1) Präerythrozytäre Impfstoffe (Pre-erythrocytic Vaccines)}

Präerythrozytäre Impfstoffe zielen sowohl auf die Sporozoitenphase als auch auf die Leberphase der Plasmodieninfek- tion. Wenn die Parasiten in dieser (asymptomatischen) Phase blockiert werden, sind ein Fortschreiten zur symptomatischen Blutphase sowie die Übertragung der Infektion nicht möglich.

\section{Untereinheitenimpfstoffe (Subunit Vaccines)}

RTS,S/AS01 besteht aus den zwei dominanten Epitopen „R“ (Repeat-Region des Circumsporozoitenproteins [CSP]) und „T“ (T-Zell-Epitop des CSP) und einem fusionierten sowie einem freien Hepatitis-B-Surface(HBs)-Antigen („S,S“). Der virusähnliche Partikel wird mit einem liposomalen Adjuvans (AS01) kombiniert [29]. Ähnlich wie der Hepatitis-B-Impfstoff wird RTS, S in einem Fermentationsverfahren in Saccharomyces cerevisiae als rekombinantes Protein hergestellt.
Das CSP-codierende Gen wurde bereits in den 1980er-Jahren von Wissenschaftlern des US-amerikanischen Walter-Reed-Army-Instituts sequenziert. In einer Kooperation mit der Firma GlaxoSmithKline (GSK) wurden Sequenzen und Konstrukte über viele Jahre in Maus und Mensch getestet. Einige Vakzinekandidaten erreichten Phase2-Studien. Da die CSP-Antigene nur schwach immunogen waren, wurde mit verschiedenen Trägern (Carrier) und Adjuvanzien experimentiert.

Die Kombination RTS,S/AS01, das heutige Mosquirix ${ }^{\mathrm{mm}}$, wurde erstmals im Jahr 2006 beim Vergleich von Adjuvanzien in Rhesusaffen publiziert [30]. Es folgte eine Reihe unterschiedlicher Studien in Maus und Mensch, die eine gute 
Verträglichkeit bei mäßiger Wirksamkeit des Impfstoffes zeigten.

Von 2009 bis 2014 ging RTS,S/AS01 in die Phase-3-Evaluierung über und wurde in elf Endemiegebieten in sieben afrikanischen Ländern an insgesamt 15.460 Säuglingen und Kleinkindern getestet. Drei Dosen RTS,S/AS01 - im Abstand von je einem Monat verabreicht - führten in den ersten 200 Tagen $z u$ einer Wirksamkeit von knapp über $50 \%$. In der insgesamt 18-monatigen Nachverfolgungsperiode reichte die Gesamteffektivität, je nach Falldefinition und Altersgruppe, von 5-45\%.

Auffällig war, dass die Wirksamkeit schnell abnahm. Bei der Gruppe der Kleinkinder (5-17 Monate alt) konnten beispielsweise bei 1000 Kindern im ersten Jahr 15-20 Fälle schwerer Malaria abgewendet werden. Im letzten halben Jahr der Nachverfolgungsperiode war dieser Effekt jedoch nicht mehr nachweisbar [31]. Bei Säuglingen (6-12 Wochen alt) wurden im letzten halben Jahr der Nachverfolgungsperiode sogar mehr schwere Malariafälle als in der Kontrollgruppe beobachtet [31].

Zwei Jahre nach dem initialen Dreidosenregime wurden die Studienkinder mit RTS,S oder Placebo einmalig nachgeimpft („geboostert“). Weitere zwei Jahre später, also vier Jahre nach der Grundimmunisierung, lag die Wirksamkeit der Impfung ohne Booster bei $28 \%$, in der Boostergruppe wurde eine Wirksamkeit von $36 \%$ berechnet [32].

Bei den durch Malaria verursachten Todesfällen wurde kein Unterschied zwischen geimpften und Kontrollkindern beobachtet. Dies war aber schon wegen der niedrigen Todesfallrate nicht möglich (4 Malariatodesfälle/15.460 Studienkinder).

Da die allgemeine Nebenwirkungsrate der Impfung sich nicht wesentlich von anderen Totimpfstoffen unterschied, wurde der Impfstoff als sicher eingeschätzt. Zwei Auffälligkeiten wurden jedoch beobachtet: 1) von 22 Meningitisfällen waren 21 in den zwei geimpften Gruppen und ein Fall in der Kontrollgruppe [33], 2) die Gesamtmortalität (All Cause Mortality) bei RTS,S-geimpften Mädchen war höher als bei RTS,S-geimpften Jungen und Kontrollkindern [34, 35].
Im Jahr 2015 bekam der Impfstoff von der European Medicines Agency (EMA) das Positivvotum, dass „die aktive Immunisierung von Kindern im Alter von 6 Wochen bis 17 Monaten gegen P.-falciparum-Malaria und Hepatitis B befürwortet werden kann“ [36].

Expertenkommissionen der WHO empfahlen daraufhin, vor der Implementierung der Vakzine in die nationalen Impfprogramme eine Evaluierung unter realen epidemiologischen und operativen Bedingungen durchzuführen. Die seit April 2019 stattfindende Phase-4Studie ist eine sog. clusterrandomisierte Studie mit dem Ziel, herauszufinden, ob die Impfung als Routineimpfung sicher ist, ob die Mortalität bei Kindern sinkt und ob es machbar ist, die 4 erforderlichen Dosen unter den gegebenen operativen Bedingungen zu verabreichen. Die Gesundheitsministerien der drei Länder Mali, Ghana und Kenia werden die Impfung in ausgewählten Regionen in die nationalen Impfprogramme integrieren [37].

\section{Ganzzellimpfstoffe (Whole Cell Vaccines)}

Ein anderer präerythrozytärer Malariaimpfstoff wird ab Anfang 2020 auf der Insel Bioko (Äquatorialguinea) in einer Phase-3-Studie getestet. Im Gegensatz zu Subunit Vaccines wie RTS,S/AS01 handelt es sich um röntgenbestrahlte, ganze P.-falciparum-Sporozoiten (PfSPZ), die intravenös injiziert werden [38].

Seit es den Forschern der amerikanischen Firma Sanaria Inc. gelingt, in großen Mengen Anophelesmücken zu züchten, diese mit Plasmodien zu infizieren, die Sporozoiten in sterilen Labors aus den Moskitos zu extrahieren, aufzureinigen und schlussendlich unter Bedingungen der Good Manufacturing Practice (GMP) einzufrieren, kann die in den 1970er-Jahren bahnbrechende Entdeckung, dass eine Immunisierung mit röntgenbestrahlten Sporozoiten zu einer sterilen Immunität gegen den Impfstamm führen kann [3], mit modernen Methoden untersucht werden. Viele der vor 50 Jahren durchgeführten Impfversuche werden nun in größerem Umfang und auf leicht unterschiedliche Weise wiederholt.
Um eine evtl. lebensgefährliche Malariainfektion mit lebenden Impfsporozoiten zu verhindern, gibt es unterschiedliche Möglichkeiten, die Sporozoiten ungefährlich zu machen, d.h. zu attenuieren:

- Chemisch attenuierte Sporozoiten (CAS, Chemically Attenuated Sporozoites): Chemisch attenuierte Parasiten - z. B. inkubiert mit Centanamycin, einem DNA-bindenden Medikament - sind noch nicht in der klinischen Erprobung am Menschen [39].

- Genetisch attenuierte Sporozoiten (GAS, Genetically Attenuated Sporozoites): Heidelberger Forschern gelang es im Jahr 2004 zum ersten Mal im Tierversuch, einen gentechnisch manipulierten Parasiten herzustellen, der in die Leber eindringt, jedoch nicht in die Blutphase übertritt [40]. Ein erster Humanversuch am Walter Reed Army Institute war nicht zufriedenstellend, da die Plasmodien bei einem von 6 Probanden in die Blutbahn gelangten und eine Malariainfektion auslösten [41]. Einer anderen Forschergruppe gelang in einem verbesserten Modell eine vollständige Attenuierung des $\mathrm{Pa}$ rasiten. Alle Freiwilligen blieben im Blutstadium negativ und entwickelten Antikörper gegen Sporozoiten [42, 43]. Der Nachweis der Wirksamkeit dieses Impfstoffes, z. B. mithilfe einer kontrollierten experimentellen Infektion am Menschen (CHMI), steht noch aus [44].

- Röntgenbestrahlte Sporozoiten (RAS, Radiation Attenuated Sporozoites): Um eine hohe Schutzrate zu erzielen, werden bei der Impfung mit röntgenbestrahlten Sporozoiten - wegen der frühen Arretierung der Sporozoiten in der Leber - mindestens 10-mal mehr Sporozoiten im Vergleich zu unbestrahlten Sporozoiten benötigt. Dafür gelten röntgenbestrahlte Sporozoiten als sicherer, da die Gefahr eines Malariadurchbruchs nicht besteht. Jüngste Studien zeigten eine hohe $(>80 \%)$ Schutzrate gegen den Impfstamm in einer kontrollierten experimentellen Infektion bei gesunden Freiwilligen (CHMI) nach 3- bis 5-maliger intravenöser Verab- 
reichung der Sporozoiten im Abstand von 4-8 Wochen. Die Schutzwirkung hielt mindestens ein Jahr an [45].

- Sporozoiteninfektion bei gleichzeitiger Gabe von Chemoprophylaxe (CPS, Chemoprophylaxis and Sporozoites): Nichtröntgenbestrahlte Sporozoiten werden durch ein geeignetes chemoprophylaktisch eingesetztes Antimalariamittel (z. B. Chloroquin) erst nach ihrem Austritt aus der Leber ins Blut abgetötet [46]. Das Immunsystem des Wirtes wird deshalb einer größeren Bandbreite von Antigenen für eine längere Zeit ausgesetzt, weshalb eine effiziente Immunantwort zu erwarten ist. Probanden, die mit voll infektiösen Sporozoiten unter Chemoprophylaxe mit Chloroquin immunisiert wurden, waren gegen eine experimentelle Malariainfektion geschützt [47-49]. Es scheint sich hierbei wohl um eine von CD8+T-Zellen-vermittelte Immunität zu handeln [50].

Die Schutzraten präerythrozytärer Ganzzellimpfstoffe sind bei Evaluierung mittels CHMI erstaunlich hoch. Allerdings wurden die meisten CHMI mit infektiösen Sporozoiten des Impfstammes (homologer Stamm) durchgeführt. In experimentellen Infektionen mit heterologen Stämmen in naiven gesunden Erwachsenen konnte jedoch gezeigt werden, dass auch eine heterologe Wirksamkeit möglich sein kann [51, 52].

In Endemiegebieten sind erst wenige Feldversuche mit Ganzzellsporozoiten durchgeführt worden. Hier gilt es u. a. herauszufinden, wie das nicht mehr naive Immunsystem auf die Impfung reagiert und wie es mit der großen Vielfalt von $\mathrm{Pa}$ rasitenstämmen zurechtkommt. So entwickelten in einem Endemiegebiet in Mali $93 \%$ der erwachsenen Placebogeimpften, aber auch $66 \%$ der Verumgeimpften eine Malaria [53]. Möglicherweise wird der Impfstoff in lebenslang malariaexponierten Erwachsenen durch das Immunsystem inaktiviert [54]. Die Ergebnisse einer in Gabun stattfindenden Studie stehen noch aus (pers. Komm.).
2) Erythrozytäre Impfstoffe (Blood Stage Vaccines)

\section{Untereinheitenimpfstoffe (Subunit Vaccines)}

Das Merozoite-Surface-Protein 1 (MSP 1) ist ein Oberflächenprotein der Merozoiten und an der Invasion von Erythrozyten beteiligt. Antikörper gegen MSP 1 schützen im Tierversuch gegen Malaria; auch in manchen Kohortenstudien korrelieren sie mit Schutz gegen Malaria [55]. Zudem konnte gezeigt werden, dass rekombinante Impfstoffe mit $\mathrm{Me}$ rozoitenantigenen (MSP 1, MSP 2 u. a.) einen sog. selektiven Druck auf die Parasitenpopulationen ausüben [56], d.h., die Stämme der geimpften Plasmodien konnten in den Infektionen spezifisch reduziert werden. Einige Kandidatenantigene für erythrozytäre Impfstoffe wurden in Phase-2-Studien untersucht, allerdings war die Wirksamkeit vernachlässigbar [57]. Allenfalls post hoc, sozusagen in Subgruppenanalysen, konnte eine mäßige Impfstoffwirksamkeit festgestellt werden.

Der einzige erythrozytäre Impfstoff, für den die Wirksamkeit in einer prospektiven Studie gezeigt werden konnte, ist GMZ 2 (Recombinant Lactococcus Lactis Hybrid Glutamate-Rich-Protein [GLURP] and Merozoite-Surface-Protein 3 [MSP 3]). Die Wirksamkeit war $14 \%$ [58] und auch ein potentes Adjuvans konnte die Wirkung von GMZ 2 in einer Evaluierung durch CHMI nicht entscheidend steigern [59]. Insgesamt zeigte sich nur eine schwache Effektivität, besonders bei jüngeren Kindern, die vor allem von einer Vakzine profitieren sollten [60]. Mit diesen Daten wurde die weitere Entwicklung des Impfstoffs eingestellt.

Die Motivation zur Entwicklung von Blutphaseimpfstoffen rührt von der Erkenntnis her, dass Personen in Endemiegebieten nach einigen Jahren einen Status erreichen, indem sie die Invasion der Parasiten in die Erythrozyten durch ihre Immunantwort kontrollieren können. Dies ist einer der Gründe, warum Erwachsene in Hochendemiegebieten kaum oder gar nicht mehr klinisch an Malaria erkranken, obwohl sie als symptomlose Träger der Plasmodien die Transmission der Parasiten aufrechterhalten. Deshalb wird weiterhin versucht, Impfstoffe gegen die Blutphase der Plasmodien zu entwickeln. So wird an der Universität Heidelberg an Subeinheiten von MSP 1 gearbeitet [61], andere Kandidaten sind das „Invasionsprotein“ RH 5 [62] und das „Camouflage“-Protein SE 36, das von japanischen Wissenschaftlern der Universität Osaka untersucht wird [63].

\section{Ganzzellimpfstoffe (Whole Cell Vaccines)}

Ganzzellimpfstoffe der Blutphase sind gleichbedeutend mit einer "Impfung“ parasitierter Erythrozyten [64]. Ein kürzlich unternommener Pilotversuch mit chemisch attenuierten (asexuellen) $\mathrm{Pa}$ rasiten der Blutphase konnte parasitenspezifische zelluläre Immunantworten in malarianaiven Freiwilligen induzieren [65].

\section{3) Transmissionsblockierende Vakzine (Transmission Blocking Vaccines)}

Nur ein kleiner Teil der asexuellen Parasiten verwandelt sich in sexuelle (männliche und weibliche) Formen (Gametozyten). Anders als ihre asexuellen Merozoitengeschwister verlassen Gametozyten die Erythrozyten nicht mehr, bevor sie nicht durch das spezielle Ambiente des Mückenmagens dazu veranlasst werden. Dort reifen sie, paaren sich und produzieren Zehntausende von Nachkommen (Sporozoiten).

Dieser Weg könnte durch Antikörper gegen Proteine blockiert werden, die sich an der Oberfläche der Plasmodien im Mückenmagen befinden. Da die Gametozyten die Erythrozyten erst im Mückenmagen verlassen, finden sich keine natürlichen Antikörper im Blut des humanen Zwischenwirtes oder lassen sich nicht natürlich boostern. Ein ausreichender Antikörperspiegel im humanen Blut, der erst im Mückenmagen wirksam wird, muss allein durch den Impfstoff aufgebaut werden.

Gemessen werden kann die transmissionsblockierende Aktivität z. B. in sog. Membranfütterungstests (Membrane Feeding Assays), in denen die natürliche Übertragung durch Anophelesmücken teilweise nachgestellt wird. Mit dieser 
Methode wurden einige Zielantigene identifiziert, so z.B. das Ookinetenprotein Pfs 25.

Für die geimpfte Person hat ein transmissionsblockierender Impfstoff (TBI) keinen direkten Nutzen (altruistische Impfung). Vergleichbar der Herdenimmunität anderer Impfstoffe hätte ein solcher Impfstoff jedoch einen wesentlichen Effekt auf die Malariaübertragung in der Bevölkerung endemischer Gebiete, wo die Transmission durch subklinische und asymptomatische Parasitenträger aufrechterhalten wird.

Eine der Hauptschwierigkeiten ist, einen ausreichend hohen und andauernden Antikörperspiegel im menschlichen Blut aufrechtzuerhalten und die Wirksamkeit in der Population zu messen, weshalb hier viel mit Adjuvanzien experimentiert wird. Einige transmissionsblockierende Impfstoffkandidaten sind in klinischen Phase-1-Studien.

\section{4) Multistadienimpfstoffe (Multi-stage Vaccines)}

Auch an deutschen Universitäten wird schon seit einigen Jahren ein Impfstoff, der alle bisher beschriebenen Stadien kombiniert, ins Auge gefasst [66]. In einem Großprojekt des Multi-Stage Malaria Vaccine Consortium (MMCV) wird diese Idee nun seit April 2018 in Oxford in die Praxis umgesetzt. In Kooperation mit Unternehmen und Forschungsorganisationen aus Frankreich, Schweden, Holland, Indien und der European Vaccine Initiative (EVI) sowie unter Beteiligung mehrerer afrikanischer Länder (u. a. Kenia, Tansania, Sierra Leone, Burkina Faso) soll bis September 2023 das Ziel erreicht werden, einen Impfstoff mit $75 \%$ iger anhaltender Wirksamkeit zu entwickeln, der die Vorgaben der Malaria Vaccine Technology Roadmap (WHO) erfüllt [67]. Der 4-Stadien-Impfstoff besteht aus

1. R 21 (präerythrozytäre, verbesserte Version von RTS,S),

2. präerythrozytärem Protein des Leberstadiums von $P$. falciparum,

3. RH 5 (Protein des Blutstadiums von P. falciparum),

4. Pfs 25 (Ookinetenprotein von P. falciparum).
$\mathrm{Zu}$ den Untereinheiten des Impfstoffes existieren publizierte Daten, jedoch wurden noch keine Resultate des Kombinationsimpfstoffes publiziert.

\section{5) Plazentaimpfstoffe (Placenta Vaccines)}

Neben Kindern unter fünf Jahren sind Schwangere und Neugeborene die Hauptleidtragenden in Malariaendemiegebieten. So ist Malaria eine der häufigsten Todesursachen für Schwangere in Endemiegebieten. Weiterhin wird angenommen, dass bis $\mathrm{zu}$ einer Million Neugeborene wegen Malaria in der Schwangerschaft mit Untergewicht geboren werden [68]. In den meisten Gebieten wurde die präventive Einnahme von Chloroquin durch die Entwicklung von Resistenzen unwirksam und auch die intermittierende Einnahme von Sulfadoxin-Pyrimethamin verliert wohl bald aus demselben Grund ihren Nutzen [69].

P. falciparum akkumuliert in der Plazenta, indem es an Chondroinsulfat A (CSA) bindet. Nach mehreren Schwangerschaften produzieren die Frauen jedoch Antikörper, die die Bindung der Parasiten an CSA blockieren können. Heute ist das Protein VAR2CSA aus der Familie der variantenreichen Oberflächenantigene (var-Genes) der erste Kandidat für einen Plazentaimpfstoff, da Antikörper gegen dieses Protein die Adhäsion der Parasiten an CSA beeinträchtigen könnten [70]. So konnte im Rahmen eines EU-finanzierten Konsortiums gezeigt werden, dass Frauen im Lauf mehrerer Schwangerschaften Antikörper gegen das Impfantigen VAR2CSA im Impfstoff PAMVAC (Pregnancy Associated Malaria Vaccine) entwickeln [71]. In einem ersten randomisierten, doppelblinden Feldexperiment am Menschen erwies sich PAMVAC als sicher und immunogen [72]. Der Nachweis der Wirksamkeit von PAMVAC (d.h. Reduktion von Komplikationen in der Schwangerschaft und Gesundheit des Neugeborenen) in einer randomisierten, doppelblinden Studie mit dem Endpunkt Krankheit steht noch aus; da nichtschwangere Frauen im gebärfähigen Alter geimpft werden, aber der
Endpunkt am Ende einer Schwangerschaft liegen würde, müsste für solch eine Studie jedoch eine vergleichsweise große Zahl an Studienteilnehmerinnen mit entsprechend langer Nachverfolgungsperiode veranschlagt werden.

\section{6) DNA-Impfstoffe (DNA Vaccines)}

Bei der Impfung mit DNA-Impfstoffen werden die Träger der Erbinformation (Nukleinsäuren) geimpft. DNA-Impfstoffe zeitigten gute Ergebnisse in der Maus [73], im Menschen konnten bisher noch keine guten Immunantworten erzeugt werden [44].

\section{Diskussion}

Je weiter entfernt der nächste Gesundheitsposten liegt, umso größer ist die Wahrscheinlichkeit, dass ein Kind mit klinischer Malaria an dieser verstirbt [74]. Dass Malaria eine tödliche Kinderkrankheit der armen Bevölkerungsteile Afrikas ist, wird auch in Veröffentlichungen der Deutschen Bundesregierung thematisiert [75]. Im Verlauf der G-20Präsidentschaft hat die Bundesregierung u.a. das Thema "globale Gesundheit" als Schwerpunkt gesetzt und diese zu einem „Markenzeichen der internationalen Verantwortung“ erklärt [76]. Mit dem Konzept „Globale Gesundheitspolitik gestalten - gemeinsam handeln Verantwortung wahrnehmen" werden „Impulse für die globale Gesundheit“ gesetzt und medizinische Autorität auf internationaler Bühne beansprucht [77, 78].

Gleichzeitig werden Afrikas große Potenziale - mit einigen der am schnellsten wachsenden Volkswirtschaften und dem größten Arbeitskräftepotenzial weltweit im Jahr 2035 - im „Marshallplan mit Afrika“ des Bundesministeriums für $\mathrm{Zu}$ sammenarbeit (BMZ) gewürdigt [79]. Die Empfehlungen eines internationalen Beratergremiums für das Bundesgesundheitsministerium (BMG) enthalten vier Schlüsselfaktoren: politische Führung, Expertise, Integration und Investitionen [80].

Drei Viertel aller Investitionen zur Bekämpfung der Malaria kommen aus den Mitteln des Globalen Fonds zur Bekämp- 
fung von Aids, Tuberkulose und Malaria [81]. Seit der Gründung des Fonds im Jahr 2002 hat Deutschland diesem mehr als 2,5 Mrd. € (Stand: Mai 2018) zur Verfügung gestellt. Mit einem Beitrag von 810 Mio. $€$ für die Jahre 2017 bis 2019 ist Deutschland nach den USA, Frankreich und Großbritannien der viertgrößte staatliche Geber des Fonds [82]. Für das Budget 2019 wurde der Jahresbeitrag der Bundesrepublik zum Fonds um 40 Mio. im Vergleich zum Vorjahr aufgestockt [83].

Die Kosten für die Entwicklung von Malariaimpfstoffen müssen jedoch hauptsächlich aus anderen Quellen bestritten werden. Dabei sind die Kosten der wissenschaftlichen Unterstützung durch europäische und amerikanische Einrichtungen schwer zu beziffern [84]. Zentrale öffentliche Förderinstitutionen sind die European and Developing Countries Clinical Trials Partnership (EDCTP) und das Bundesministerium für Bildung und Forschung (BMBF). Leider hat das $\mathrm{BMBF}$ bis dato keine eigene Förderlinie für die Malariaimpfstoffentwicklung.

Für die Produktbereitstellung von Mosquirix $^{\text {mis }}$ veranschlagt GSK 20 Mio. US-Dollar (5 US-Dollar pro Impfdosis; [84]). Ob dieser Impfstoff letztendlich auf den Markt kommt oder eingesetzt wird, soll entschieden werden, wenn die Ergebnisse der laufenden Phase-4Studie ausgewertet sind. Bei dieser Untersuchung sollen neben der organisatorischen Machbarkeit von vier Impfungen in festgelegten zeitlichen Abständen die Fragen nach den Meningitisfällen und dem Effekt auf die Gesamtmortalität, inklusive der geschlechtsspezifischen Effekte, beantwortet werden [85]. Expertenkommissionen rieten davon ab, den Impfstoff bei Säuglingen anzuwenden, da die Wirksamkeit in dieser Altersgruppe zu niedrig sei [85].

Ein zentraler Punkt in der Diskussion um Malariaimpfstoffe ist die Definition der Wirksamkeit. In den meisten Studien wurde die protektive Effektivität auf die Reduktion der ersten oder einzigen Episode einer Malaria nach Impfung bezogen. Das entspricht nicht einer Reduktion der Inzidenz, da bei langem Followup und/oder hoher Endemizität zahlreiche Episoden auftreten können. So kann beispielsweise eine $30 \%$ ige Wirksamkeit bedeuten, dass sich der kumulative Anteil der Malariaepisoden zwischen Geimpften und Nichtgeimpften nur um $10 \%$ unterscheidet.

Erfahrungsgemäß ist beim Übergang von Phase-3- zu Phase-4-Studien eine geringere Impfstoffwirksamkeit zu erwarten, da die Heterogenität der Studienpopulation größer wird. Zudem kann die praktische Verabreichung der Impfung in nationalen Impfprogrammen nicht mehr in ähnlicher Weise wie in Phase-3-Studien kontrolliert werden. Des Weiteren könnten die Menschen im Glauben, geschützt zu sein, sich weniger mit Moskitonetzen schützen. Auch dies würde die Impfstoffwirksamkeit niedriger erscheinen lassen. Im Gegensatz dazu können auch positive Begleiteffekte der Impfkampagne eintreten, wie z.B. ein verbesserter Schutz durch gleichzeitige Verteilung von Moskitonetzen oder durch die kampagnenbegleitende, regelgerechte Durchführung frühzeitiger Diagnose und korrekter Behandlung der Malaria. Dann wiederum erschiene die Impfstoffwirksamkeit größer, als sie in Wirklichkeit ist. In Abwesenheit einer verblindeten, randomisierten Kontrollgruppe wird es also nicht leichtfallen, die tatsächliche Impfstoffwirksamkeit aus der Phase-4Studie abzuleiten.

Schon jetzt ist offensichtlich, dass der Impfstoff RTS,S nur als Begleitinstrument in einem Konzert von Maßnahmen zur Malariakontrolle zum Zuge kommen kann. Dies ist jedoch nichts Ungewöhnliches. So wurden auch die Pocken - anders als das gängige Narrativ es glauben macht - nicht allein durch den Impfstoff eradiziert, sondern im Zusammenspiel der Impfung mit immensen und letztendlich weltweiten Fallidentifizierungs- und Isolierungsmaßnahmen, was schließlich als Ringvakzinierung Eingang in die Geschichtsbücher fand [86-89].

Die Konfidenzintervalle der Phase-3Studie von RTS,S reichten teilweise in den Minusbereich, sodass negative Effekte nicht ausgeschlossen werden können. Da es sich um statistische Wahrscheinlichkeiten handelt, ist es schwierig, definitive Aussagen zu treffen. Tatsächlich wurden in der Gruppe der Säuglinge (6-12 Wochen alt) während des letz- ten halben Jahres der Nachverfolgungsperiode mehr schwere Malariafälle als bei der ungeimpften Gruppe beobachtet [31]. Dieser Negativeffekt war in anderer Darstellung derselben statistischen Daten nicht mehr sichtbar [32].

Neben der bereits beschriebenen Häufung von Meningitis in den geimpften Gruppen wirft die höhere Mortalität weiblicher Studienkinder Fragen auf [34, 35]. Unspezifische Negativeffekte von Totimpfstoffen, auch geschlechtsabhängig, wurden schon anderweitig beschrieben $[90,91]$. Da die geimpften Kinder fünf und sechs Jahre nach der Impfung ein höheres Risiko für Malariaattacken hatten als ungeimpfte Kinder [92], sollte auch Hinweisen auf einen Reboundeffekt nachgegangen werden. Zwar konnte ein spezifischer Schutz vor Stämmen gezeigt werden, die den Impfantigenen ähnelten, der in den ersten 200 Tagen sogar die 50Prozent-Marke überstieg. Dieser Schutz nahm jedoch schnell ab und fiel in hochendemischen Gebieten geringer aus als in niedriger endemischen Gebieten [13].

Dass Impfstoffe wirksam sind, kann nicht bezweifelt werden. Leicht verständlich ist auch die Tendenz, positive Effekte positiv herauszustellen. So konnte selbst bei dem zuerst viel gepriesenen, dann aber unwirksamen SPf-66-Impfstoff eine Reduzierung der Stammvielfalt der Infektionen in Geimpften festgestellt werden [93]. Für die Anwendung in nationalen Impfprogrammen müssen jedoch klare Kriterien gelten. Insofern kann es als weise Entscheidung der WHO angesehen werden, positive und negative Effekte der RTS,S-Vakzine in einer breitflächigen Evaluierung unter realen, praktischen Bedingungen zu überprüfen.

Auch bei präerythrozytären Ganzzellimpfstoffen (PfSPZ) sind noch viele Fragen offen. Die aufwendige und kostentreibende Herstellung und Lagerung der Sporozoiten (manuelle Extraktion lebender Sporozoiten aus Anophelesmoskitos, Tiefkühlkette bei $-180^{\circ} \mathrm{C}$ ) sowie die dreimalige intravenöse Verabreichung würde den flächendeckenden Einsatz selbst bei einer hohen Wirksamkeit der Impfung ( $>75 \%)$ schwierig gestalten. Bei einer geringeren Wirksamkeit, wie sie bisher in wenigen Studien in Afrika beobachtet wurde, ist es fraglich, 
ob die Impfstoffe in die nationalen Impfprogramme malariaendemischer Länder aufgenommen werden können. Der internationale Tourismus kommt schon wegen der intravenösen Verabreichung als Absatzmarkt nicht infrage. Zudem liegen nur wenige Reiseziele in Hochendemiegebieten. Ein möglicher Einsatz der attenuierten Sporozoiten wäre in der militärmedizinischen Versorgung zu sehen, die sich schon immer um Schutz vor Malaria und um deren Behandlung bemühte [94].

Kosten sind ein wesentlicher Faktor für den Einsatz eines Malariaimpfstoffes. Als Alternative zu RTS,S und röntgenbestrahlten Sporozoiten wäre in diesem Kontext in der Gruppe der präerythrotzytären Impfstoffe der Kandidat R $21 \mathrm{zu}$ nennen (s. Kombinationsimpfstoffe), der vermutlich ein ähnliches Profil wie RTS,S zeigt, aber nicht als geistiges Eigentum (Intellectual Property) eines Pharmakonzerns geführt wird.

$\mathrm{Ob}$ es gelingt, die Blutstadien der $\mathrm{Pa}$ rasiten mit einer Impfung zu bekämpfen, was dem menschlichen Immunsystem in den letzten zehntausend Jahren nicht gelungen ist, bleibt eine philosophische Frage, da erst geringfügige Wirksamkeiten der Impfstoffkandidaten nachgewiesen wurden. Ob solche Impfstoffkandidaten weiterentwickelt werden, wird sich wohl entscheiden, wenn die Ergebnisse der Phase-4-RTS,S-Studie vorliegen.

Anders stellt sich die Frage bei transmissionsblockierenden Impfstoffen, da hier etwas versucht wird, was in der Natur nur ausnahmsweise vorkommt, nämlich eine Immunantwort in einem Organismus (Mensch) hervorzurufen, die erst in einem anderen Organismus (Mücke) greifen soll. Hier liegen inzwischen zwar faszinierende Vorversuche vor, aber noch keine konkreten Ergebnisse von praktischer Bedeutung.

Verlockend ist die Logik der Multistadienimpfstoffe: Wenn Einzelimpfstoffe gegen die jeweiligen Stadien nur kleine Erfolge verbuchen, liegt es nahe, diese Erfolge $\mathrm{zu}$ addieren, um über die Schwelle von $75 \%$ Wirksamkeit zu kommen. Dieser Ansatz des MMCV wird in den kommenden Jahren von der EDCTP unterstützt [95]. Es ist jedoch nicht zwangsläufig zu erwarten, dass sich vier minima- le bzw. nichtvorhandene Wirksamkeiten zu einer anhaltenden Wirksamkeit von über $75 \%$ addieren. Trotzdem sollte dieser Ansatz weiterverfolgt werden, da er der Logik der modernen Impfstoffentwicklung entspricht.

Der Einsatz von Plazentaimpfstoffen wäre eine lebensrettende Maßnahme für werdende Mütter und Neugeborene in Hochendemiegebieten. Nach erfolgreichen randomisierten, doppelblinden Studien zur Sicherheit und Immunogenität der Impfung wäre es konsequent, eine Studie zur Wirksamkeit der Impfung bei Malaria von Schwangeren durchzuführen.

DNA- und vor allem RNA-Vakzinen sind generell noch entwicklungsfähig, so auch gegen Malaria. Die Schwierigkeit ist, durch die Verimpfung von Nukleinsäuren eine effektive Immunantwort im zellulären oder humoralen Bereich zu erzeugen. Dies ist bisher noch nicht überzeugend gelungen. Möglicherweise wird sich dies mit der Entwicklung eines innovativen mRNA-basierten Impfstoffs auf der Plattform der Tübinger Firma CureVac AG ändern, die dafür von der Bill-\&Melinda-Gates-Stiftung unterstützt wird [96].

Was bei Fachgesprächen unter Malariologen gelegentlich zur Sprache kommt, aber nicht konsequent ausdiskutiert wird, ist die beeindruckend hohe Wirksamkeit der Placeboimpfung gegen Tod durch Malaria. Ironisch überspitzt wird damit die Tatsache angesprochen, dass in der Phase-3-Studie zur Evaluierung von RTS,S in hochendemischen Gebieten die Malariamortalität extrem gering war: 4 Kinder von 15.460 Kindern sind in beiden Studienarmen (RTS,S und Placebo) an Malaria gestorben, d.h., die Malariamortalität war bei allen Studienkindern signifikant geringer als in der Studienumgebung. Hier zeigt sich die Wirkung einfacher Mittel einer funktionierenden Gesundheitsversorgung: Alle Studienkinder schliefen unter imprägnierten Moskitonetzen und wurden schnell und richtig diagnostiziert und behandelt.

\section{Fazit}

Mit RTS,S/AS01 wird erstmals ein mäßig wirksamer Impfstoff großflächig gegen Malaria eingesetzt. Die Ergebnisse der Phase-4-Studie werden zeigen, ob damit ein praktischer Einsatz in Malariakontrollprogrammen gerechtfertigt ist oder ob ein weiterer Rückschlag in der langen Geschichte der Entwicklung von Malariaimpfstoffen verbucht werden muss [97]. Die Prognosen innerhalb der Gemeinschaft der Malariaforscher im Hinblick auf die Frage, ob es bald einen wirksamen Malariaimpfstoff geben wird, bewegen sich von tiefem Zweifel bis zu euphorischer Begeisterung. Es bleibt damit spannend.

\section{Korrespondenzadresse}

Wolfram Gottfried Metzger

Institut für Tropenmedizin, Reisemedizin und

Humanparasitologie, Kompetenzzentrum

Tropenmedizin Baden-Württemberg,

Universitätsklinikum Tübingen

Wilhelmstraße 27, 72074 Tübingen,

Deutschland

wolfram.metzger@uni-tuebingen.de

Danksagung. Wir danken unserer Skriptora Ingrid Heesen für das Korrekturlesen des Manuskriptes.

\section{Einhaltung ethischer Richtlinien}

Interessenkonflikt. W. Metzger, Z. Sulyok, A. Theurer und C. Köhler geben an, dass kein Interessenkonflikt besteht.

Bei der Abfassung dieser Arbeit wurden alle ethischen Richtlinien eingehalten.

\section{Literatur}

1. Sergent E, Sergent E (1910) Sur l'immunite sdans le paludismedes oiseaux. Conservation in vitro des sporozoites de plasmodium de Plasmodium relictum immmunite relative obtenue par inoculations de ces sporozoites. CR Acad Sci 151:407-409

2. Nussenzweig RS, Vanderberg J, Most H, Orton C (1967) Protective immunity produced by the injection of $x$-irradiated sporozoites of plasmodium berghei. Nature 216(5111):160-162

3. Clyde DF, Most H, McCarthy VC, Vanderberg JP (1973) Immunization of man against sporoziteinduced falciparum malaria. Am J Med Sci 266(3):169-177

4. Zavala F, Tam JP, Hollingdale MR et al (1985) Rationale for development of a synthetic vaccine against Plasmodium falciparum malaria. Science 228(4706):1436-1440 
5. Nussenzweig RS, Godson GN, Nussenzweig V (1984) United States Patent Patent Number: 4,466,917 Date of Patent Aug. 21

6. Ballou WR, Cahill CP (2007) Two decades of commitment to malaria vaccine development: glaxosmithkline biologicals. American Society of Tropical Medicine and Hygiene. https://www. ncbi.nlm.nih.gov/books/NBK1706/. Zugegriffen: 1. Nov. 2019

7. Brown P Scientist whose dream of beating disease came true (1999) The Guardian. https://www. theguardian.com/uk/1999/jul/24/paulbrown. Zugegriffen: 1.Nov. 2019

8. Graves P, Gelband H (2006) Vaccines for preventing malaria (SPf66). Cochrane Database Syst Rev. https://doi.org/10.1002/14651858.CD005966

9. Bojang KA, Obaro SK, Leach A et al (1997) Followup of Gambian children recruited to a pilot safety and immunogenicity study of the malaria vaccine SPf66. Parasite Immunol 19(12):579-581

10. Metzger WG, Haywood M, D'Alessandro U et al (1999) Serological responses of Gambian children to immunization with the malaria vaccine SPf66. Parasite Immunol 21(7):335-340

11. Moorthy VS, Newman RD, Okwo-Bele J-M (2013) Malaria vaccine technology roadmap. Lancet 382(9906):1700-1701

12. Maher $B(2008)$ Malaria: the end of the beginning. Nature 451(7182):1042-1046

13. von Seidlein $L$ (2019) The advanced development pathway of the RTS,S/AS01 vaccine. Methods Mol Biol 2013:177-187

14. Adepoju P (2019) RTS,S malaria vaccine pilots in three African countries. Lancet 393(10182):1685

15. Robert Koch-Institut (RKI) (2017) Infektionsepidemiologisches Jahrbuch meldepflichtiger Krankheiten für 2017. www.rki.de/jahrbuch. Zugegriffen: 1.Nov. 2019

16. Lalremruata A, Magris $M$, Vivas-Martínez $S$ et al (2015) Natural infection of Plasmodium brasilianum in humans: man and monkey share quartan malaria parasites in the Venezuelan Amazon. EBioMedicine 2(9):1186-1192

17. Metzger WG, Ehni H-J, Kremsner PG, Mordmueller BG (2020) Experimental infections in humans - historical and ethical reflections. Trop Med Int Health. https://doi.org/10.1111/tmi. 13320

18. Mordmüller B, Surat G, Lagler H et al (2017) Sterile protection against human malaria by chemoattenuated PfSPZ vaccine. Nature 542(7642):445-449

19. Müller O, Lu GY, von Seidlein L (2019) Geographic expansion of artemisinin resistance. J Travel Med. https://doi.org/10.1093/jtm/taz030

20. Romay-Barja M, Cano J, Ncogo P et al (2016) Determinants of delay in malaria care-seeking behaviour for children 15 years and under in Bata district, Equatorial Guinea. Malar J 15:187

21. Worrall E, Basu S, Hanson K (2005) Is malaria a disease of poverty? A review of the literature. Trop Med Int Health 10(10):1047-1059

22. Rothe C, Boecken G, Rosenbusch D et al (2019) Empfehlungen zur Malariaprophylaxe. Flug Reisemed 26(3):105-132

23. Trape JF, Rogier C, Konate L et al (1994) The Dielmo project: a longitudinal study of natural malaria infection and the mechanisms of protective immunity in a community living in a holoendemic area of Senegal. Am J Trop Med Hyg 51 (2):123-137

24. Langhorne J, Ndungu FM, Sponaas A-M, Marsh K (2008) Immunity to malaria: more questions than answers. Nat Immunol 9(7):725-732

25. WHO Tables of malaria vaccine projects globally. WHO. http://www.who.int/immunization/
research/development/Rainbow_tables/en/. Zugegriffen: 11. Aug. 2019

26. Cockburn IA, Seder RA (2018) Malaria prevention: from immunological concepts to effective vaccines and protective antibodies. Nat Immuno 19(11):1199-1211

27. WHO Malaria vaccines. http://www.who.int/ immunization/research/development/malaria/ en/.Zugegriffen: 31.Juli 2019

28. Wilson KL, Flanagan KL, Prakash MD, Plebanski M (2019) Malaria vaccines in the eradication era: current status and future perspectives. Expert Rev Vaccines 18(2):133-151

29. Ballou WR, Rothbard J, Wirtz RA et al (1985) Immunogenicity of synthetic peptides from circumsporozoite protein of Plasmodium falciparum. Science 228(4702):996-999

30. Stewart VA, McGrath SM, Walsh DS et al (2006) Preclinical evaluation of new adjuvant formulations to improve the immunogenicity of the malaria vaccine RTS,S/AS02A. Vaccine 24(42-43):6483-6492

31. RTS,S Clinical Trials Partnership (2014) Efficacy and safety of the RTS,S/AS01 malaria vaccine during 18 months aftervaccination: a phase 3 randomized, controlled trial in children and young infants at 11 African sites. PLoSMed 11(7):e1001685

32. RTS,S Clinical Trials Partnership (2015) Efficacy and safety of RTS,S/AS01 malaria vaccine with or without a booster dose in infants and children in Africa: final results of a phase 3 , individually randomised, controlled trial. Lancet 386(9988):31-45

33. Müller O, Tozan Y, Becher H (2015) RTS,S/AS01 malaria vaccine and child mortality. Lancet 386(10005):1736

34. Aaby P, Rodrigues A, Kofoed P-E, Benn CS (2015) RTS,S/AS01 malaria vaccine and child mortality. Lancet 386(10005):1735-1736

35. Klein SL, Shann F, Moss WJ, Benn CS, Aaby P (2016) RTS,S Malaria Vaccine and Increased Mortality in Girls. mBio 7(2):e514-e516

36. European Medicines Agency (2018) Mosquirix H-W-2300. https://www.ema.europa.eu/en/ mosquirix-h-w-2300.Zugegriffen: 1. Nov. 2019

37. Mesa (2019) Large-scale implementation of the RTS,S malaria vaccine: phase IV trial. https://mesamalaria.org/mesa-track/large-scaleimplementation-rtss-malaria-vaccine-phase-ivtrial.Zugegriffen: 1.Nov. 2019

38. Butler D (2019) Promising malaria vaccine to be tested in first large field trial. Nature. http:// www.nature.com/articles/d41586-019-01232-4. Zugegriffen: 1. Nov. 2019

39. Purcell LA, Wong KA, Yanow SK, Lee M, Spithill TW, Rodriguez A (2008) Chemically attenuated Plasmodium sporozoites induce specific immune responses, sterile immunity and cross-protection against heterologous challenge. Vaccine 26(38):4880-4884

40. Mueller A-K, Labaied M, KappeSHI,MatuschewskiK (2005) Genetically modified Plasmodium parasites as a protective experimental malaria vaccine. Nature 433(7022):164-167

41. Spring M, Murphy J, Nielsen R et al (2013) Firstin-human evaluation of genetically attenuated Plasmodium falciparum sporozoites administered by bite of Anopheles mosquitoes to adult volunteers. Vaccine 31(43):4975-4983

42. Mikolajczak SA, Lakshmanan V, Fishbaugher $M$ et al (2014) A next-generation genetically attenuated plasmodium falciparum parasite created by triple gene deletion. Mol Ther 22(9):1707-1715

43. Kublin JG, Mikolajczak SA, Sack BK et al (2017) Complete attenuation of genetically engineered
Plasmodium falciparum sporozoites in human subjects. Sci Transl Med. https://doi.org/10.1126/ scitranslmed.aad9099

44. Goh YS, McGuire D, Rénia L (2019) Vaccination With Sporozoites: Models and Correlates of Protection. Front Immunol 10:1227

45. Ishizuka AS, Lyke KE, DeZure A et al (2016) Protection against malaria at 1 year and immune correlates following PfSPZ vaccination. Nat Med 22(6):614-623

46. Rénia L, Grüner AC, Mauduit M, Snounou G (2013) Vaccination using normal live sporozoites under drug treatment. Methods Mol Biol 923:567-576

47. Roestenberg M, McCall M, Hopman J et al (2009) Protection against a malaria challenge by sporozoite inoculation. N Engl J Med 361 (5):468-477

48. Roestenberg M, Teirlinck AC, McCall MBB et al (2011) Long-term protection against malaria after experimental sporozoite inoculation: an open-label follow-up study. Lancet 377(9779):1770-1776

49. Bijker EM, Bastiaens GJH, Teirlinck AC (2013) Protection against malaria after immunization by chloroquine prophylaxis and sporozoites is mediated by preerythrocytic immunity. Proc Natl Acad SciUSA 110(19):7862-7867

50. Epstein JE, Tewari K, Lyke KE et al (2011) Live attenuated malaria vaccine designed to protect through hepatic $\mathrm{CD} 8^{+} \mathrm{T}$ cell immunity. Science 334(6055):475-480

51. Epstein JE, Paolino KM, Richie TL et al (2017) ProtectionagainstPlasmodiumfalciparum malaria by PfSPZ Vaccine. JCI Insight 2(1):e89154

52. Lyke KE, Ishizuka AS, Berry AA et al (2017) Attenuated PfSPZ Vaccine induces strain-transcending $T$ cells and durable protection against heterologous controlled human malaria infection. Proc Natl Acad SciUSA 114(10):2711-2716

53. Sissoko MS, Healy SA, Katile A (2017) Safety and efficacy of PfSPZ Vaccine against Plasmodium falciparum via direct venous inoculation in healthy malaria-exposed adults in Mali: a randomised, double-blind phase 1 trial. Lancet Infect Dis 17(5):498-509

54. Olotu A, Urbano V, Hamad A et al (2018) Advancing global health through development and clinical trials partnerships: a randomized, placebo-controlled, double-blind assessment of safety, Tolerability, and Immunogenicity of pfSPZ vaccine for malaria in healthy Equatoguinean men. Am J Trop Med Hyg 98(1):308-318

55. Beeson JG, Drew DR, Boyle MJ, Feng G, Fowkes FJI, Richards JS (2016) Merozoite surface proteins in red blood cell invasion, immunity and vaccines against malaria. FEMS Microbiol Rev 40(3):343-372

56. Genton B, Betuela I, Felger I et al (2002) A recombinant blood-stage malaria vaccine reduces Plasmodium falciparum density and exerts selective pressure on parasite populations in a phase 1-2b trial in Papua New Guinea. J INFECT DIS 185(6):820-827

57. Ogutu BR, Apollo OJ, McKinney D et al (2009) Blood stage malaria vaccine eliciting high antigenspecific antibody concentrations confers no protection to young children in Western Kenya. PLoSONE 4(3):e4708

58. Sirima SB, Mordmüller B, Milligan P et al (2016) A phase $2 b$ randomized, controlled trial of the efficacy of the GMZ2 malaria vaccine in African children. Vaccine 34(38):4536-4542

59. Dejon-Agobe JC, Ateba-Ngoa U, Lalremruata A et al (2018) Controlled human malaria infection of healthy lifelong malaria-exposed adults to assess safety, immunogenicity and efficacy of the asexua 
blood stage malaria vaccine candidate GMZ2. Clin Infect Dis. https://doi.org/10.1093/cid/ciy1087

60. Theisen M, Adu B, Mordmüller B, Singh S (2017) The GMZ2 malaria vaccine: from concept to efficacy in humans. Expert Rev Vaccines 16(9):907-917

61. Jäschke A, Coulibaly B, Remarque EJ, Bujard H, Epp C (2017) Merozoite surface protein 1 from plasmodium falciparum is a major target of opsonizing antibodies in individuals with acquired immunity against malaria. Clin Vaccine Immunol. https://doi.org/10.1128/CVI.00155-17

62. Payne RO, Silk SE, Elias SC et al (2019) Human vaccination against $\mathrm{RH} 5$ induces neutralizing antimalarial antibodies that inhibit $\mathrm{RH} 5$ invasion complex interactions. JCI Insight. https://doi.org/ 10.1172/jci.insight.96381

63. Tougan T, Edula JR, Takashima E et al (2018) Molecular camouflage of plasmodium falciparum merozoites by binding of host vitronectin to P47 fragment of SERA5. Sci Rep. https://doi.org/10. 1038/s41598-018-23194-9

64. Pombo DJ, Lawrence $G$, Hirunpetcharat $C$ et al (2002) Immunity to malaria after administration of ultra-low doses of red cells infected with Plasmodium falciparum. Lancet 360(9333):610-617

65. Stanisic DI, Fink J, Mayer J et al (2018) Vaccination with chemically attenuated Plasmodium falciparum asexual blood-stage parasites induces parasite-specific cellular immune responses in malaria-naïve volunteers: a pilot study. BMC Med 16(1):184

66. Boes A, Spiegel H, Voepel N et al (2015) Analysis of a multi-component multi-stage malaria vaccine candidate-tackling the cocktail challenge. PLoS ONE 10(7):e131456

67. Multi-Stage Malaria Vaccine Consortium: field efficacy testing of a malaria vaccine targeting all four stages of the parasite's life-cycle-ERALEARN. https://www.era-learn.eu/networkinformation/networks/edctp-ii/vaccines-forpoverty-related-diseases-prds/multi-stagemalaria-vaccine-consortium-field-efficacytesting-of-a-malaria-vaccine-targeting-all-fourstages-of-the-parasites-life-cycle. Zugegriffen: 12. August 2019

68. Pehrson C, Salanti A, Theander TG, Nielsen MA (2017) Pre-clinical and clinical development of the first placental malaria vaccine. Expert Rev Vaccines 16(6):613-624

69. Fried M, Duffy PE (2017) Malaria during pregnancy. Cold Spring Harb Perspect Med. https://doi.org/ 10.1101/cshperspect.a025551

70. Fried M, Duffy PE (2015) Designing a VAR2CSAbased vaccine to prevent placental malaria. Vaccine 33(52):7483-7488

71. Gbédandé K, Fievet N, Viwami F et al (2017) Clinical development of a VAR2CSA-based placental malaria vaccine PAMVAC: quantifying vaccine antigenspecific memory B \& T cell activity in Beninese primigravidae. Vaccine 35(27):3474-3481

72. Mordmüller B, Sulyok $M$, Egger-Adam $D$ et al (2019) First-in-human, randomized, double-blind clinical trial of differentially adjuvanted PAMVAC, a vaccine candidate to prevent pregnancyassociated malaria. Clin Infect Dis. https://doi.org/ 10.1093/cid/ciy1140

73. Richie TL, Charoenvit Y, Wang Ret al (2012) Clinical trial in healthy malaria-naïve adults to evaluate the safety, tolerability, immunogenicity and efficacy of MuStD05, a five-gene, sporozoite/hepatic stage Plasmodium falciparum DNA vaccine combined with escalating dose human GM-CSF DNA. Hum Vaccin Immunother 8(11):1564-1584
74. O'Meara WP, Noor A, Gatakaa H, Tsofa B, McKenzie FE, Marsh K (2009) The impact of primary health care on malaria morbidity-defining access by disease burden. Trop Med Int Health 14(1):29-35

75. Bundesregierung In die Zukunft investieren: Malaria besiegen. https://www.bundesregierung.de/ breg-de/aktuelles/in-die-zukunft-investierenmalaria-besiegen-438820. Zugegriffen: 5. Aug. 2019

76. Gröhe H Gemeinsame Verantwortung der G20-Partnerländer für die globale Gesundheit". Bundesgesundheitsministerium. https:// www.bundesgesundheitsministerium.de/ presse/pressemitteilungen/2016/4-quartal/g20praesidentschaft.html.Zugegriffen:6.Aug. 2019

77. Bundesregierung (2013) Globale Gesundheitspolitikgestalten, gemeinsam handeln, Verantwortung wahrnehmen: Konzept der Bundesregierung. Publikationsversand der Bundesregierung, Rostock

78. Kickbusch I, Franz C, Holzscheiter A et al (2017) Germany's expanding role in global health. Lancet 390(10097):898-912

79. BMZ (2019) Marshallplan mit Afrika. http://www. bmz.de/de/laender_regionen/marshallplan mit_afrika/index.html.Zugegriffen:6.Aug. 2019

80. IAB (2019) Erklärung des Internationalen Beratergremiums zu globaler Gesundheit

81. Global Fund (2019) Global fund overview. https://www.theglobalfund.org/en/overview/. Zugegriffen:7. Aug. 2019

82. BMZ (2019) Globaler Fonds zur Bekämpfung von Aids, Tuberkulose und Malaria. http://www. bmz.de/de/ministerium/wege/multilaterale_ez/ akteure/wio/gfatm/index.html. Zugegriffen: 7. Aug. 2019

83. BMZ(2018) EntwicklungsministerMüllersagtneue Unterstützung im Kampf gegen Aids zu. http:// www.bmz.de/de/presse/aktuelleMeldungen/ 2018/november/181130_EntwicklungsministerMueller-sagt-neue-Unterstuetzung-im-Kampfgegen-AIDS-zu/index.html. Zugegriffen: 7. Aug 2019

84. Deutscher Bundestag (2017) Bericht des Ausschusses für Bildung, Forschung und Technikfolgenabschätzung (18. Ausschuss) gemäß § 56a derGeschäftsordnung Technikfolgenabschätzung (TA) Neue Arzneimittel gegen vernachlässigte Krankheiten Endbericht zum TA-Projekt "Medikamente für Afrika“.http://dip21.bundestag.de/ dip21/btd/18/123/1812306.pdf. Zugegriffen: 7. August 2019

85. WHO (2018) Malaria vaccine: WHO position paper, January 2016-Recommendations. Vaccine 36(25):3576-3577

86. Fenner F, Henderson DA, Arita I, Jezek Z, Ladnyi ID, WHO (1988) Smallpox and its eradication. World Health Organization. https://apps.who.int/iris/ handle/10665/39485.Zugegriffen: 22. Juni 2019

87. Baxby D (1999) The end of smallpox. Hist Today 49(3):14-16

88. Henderson DA (2009) Smallpox: the death of a disease. The inside story of eradicating a world wide killer, 1. Aufl. Prometheus Books, Amherst, New York

89. Metzger WG, Köhler C, Mordmüller B (2015) Lessons from a modern review of the smallpox eradication files. JR Soc Med 108(12):473-477

90. Aaby P, Ravn H, Fisker AB, Rodrigues A, Benn CS (2016) Is diphtheria-tetanus-pertussis (DTP) associated with increased female mortality? A meta-analysis testing the hypotheses of sexdifferential non-specific effects of DTP vaccine. Trans RSoc Trop Med Hyg 110(10):570-581
91. Aaby P, Nielsen J, Benn CS, Trape J-F (2016) Sex-differential effects on mortality of BCG and diphtheria-tetanus-pertussis vaccines in a rural area with high vaccination coverage: observational study from Senegal. Trans R Soc Trop Med Hyg 110(9):527-533

92. Olotu A, Fegan G, Wambua J (2016) Sevenyear efficacy of RTS,S/AS01 malaria vaccine among young African children. N Engl J Med 374(26):2519-2529

93. Haywood M, Conway DJ, Weiss H et al (1999) Reduction in the mean number of plasmodium falciparum genotypes in Gambian children immunized with the malaria vaccine SPf66. Trans $R$ Soc Trop Med Hyg 93(Suppl 1):65-68

94. Ratto-Kim S, Yoon I-K, Paris RM, Excler J-L, Kim JH, O'Connell RJ (2018) The US military commitment to vaccine development: a century of successes and challenges. Front Immunol 9:1397

95. EDCTP (2019) Malaria portfolio: large investments in treatment and vaccines. EDCTP. http:// www.edctp.org/news/edctp-malaria-portfoliolarge-investments-in-treatment-and-vaccine/. Zugegriffen: 12. Aug. 2019

96. CureVac (2019) CureVac entwickelt innovative mRNA-Impfstoffe gegen Influenza und Malaria. https://www.curevac.com/de/newsroom/news/ curevac-entwickelt-innovative-mrna-impfstoffegegen-influenza-und-malaria/. Zugegriffen: 12 Aug. 2019

97. Maxmen A (2019) First proven malaria vaccine rolled out in Africa-but doubts linger. Nature 569:14-15 